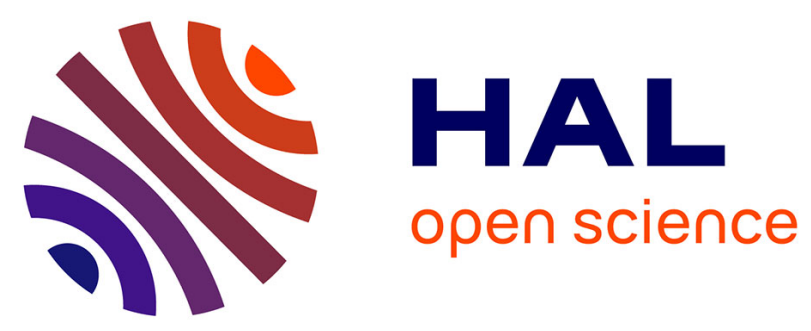

\title{
Monitoring methanol-induced protein unfolding by fluorescence anisotropy measurements of covalently labelled rhodamine probe
}

Antonin Soleilhac, Franck Bertorelle, Philippe Dugourd, Marion Girod, Rodolphe Antoine

\section{To cite this version:}

Antonin Soleilhac, Franck Bertorelle, Philippe Dugourd, Marion Girod, Rodolphe Antoine. Monitoring methanol-induced protein unfolding by fluorescence anisotropy measurements of covalently labelled rhodamine probe. The European Physical Journal D : Atomic, molecular, optical and plasma physics, 2017, 71 (6), 10.1140/epjd/e2017-70760-3 . hal-01569441

\section{HAL Id: hal-01569441 \\ https://hal.science/hal-01569441}

Submitted on 1 Nov 2020

HAL is a multi-disciplinary open access archive for the deposit and dissemination of scientific research documents, whether they are published or not. The documents may come from teaching and research institutions in France or abroad, or from public or private research centers.
L'archive ouverte pluridisciplinaire $\mathbf{H A L}$, est destinée au dépôt et à la diffusion de documents scientifiques de niveau recherche, publiés ou non, émanant des établissements d'enseignement et de recherche français ou étrangers, des laboratoires publics ou privés. 


\title{
Monitoring Methanol-induced protein unfolding by fluorescence anisotropy measurements of covalently labelled rhodamine probe.
}

\author{
Antonin Soleilhac, a) Franck Bertorelle, a) Philippe Dugourd, a) Marion Girod, \\ and Rodolphe Antoine ${ }^{\text {a)* }}$ \\ a) Institut lumière matière, UMR5306 Université Claude Bernard Lyon1-CNRS, Université de Lyon 69622 Villeurbanne \\ cedex, France. \\ b) Univ Lyon, CNRS, Université Claude Bernard Lyon 1, Ens de Lyon, Institut des Sciences Analytiques, UMR 5280, 5 \\ rue de la Doua, F-69100 VILLEURBANNE, France.
}

\section{An invited contribution to}

European Physical Journal D (EPJD) Special Issue: Dynamics of Systems on the Nanoscale, http://www.epj.org/open-calls-for-papers/100-epj-d/1084-epjd-special-issue-dynamics-of-systems-onthe-nanoscale

\begin{abstract}
We describe the use of an extrinsic fluorophore (Rhodamine B isothiocyanate) as a versatile probe to measure rotational motions of proteins. To illustrate the usefulness of this probe, we describe the fluorescence anisotropy values of this fluorophore covalently linked to myoglobin protein measured in aqueous solutions of increased methanol content. Methanol-induced unfolding is revealed by the transition from constrained to free rotation of the covalently attached rhodamine B fluorophore.
\end{abstract}

\section{Graphical abstract}
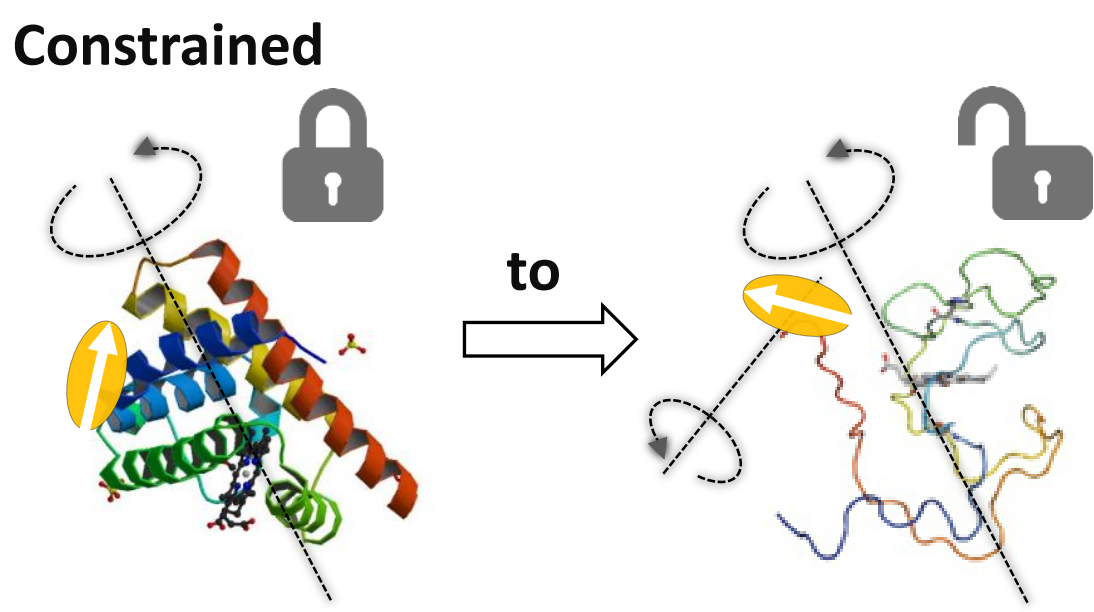

Free 


\section{Introduction:}

Protein conformational dynamics regulate protein function. Therefore, tools able to probe internal dynamics of proteins, in the picosecond to microsecond timescale are highly desirable. Fluorescence spectroscopy has become an established tool to investigate the dynamics and interactions of biomolecules. ${ }^{1}$ In particular, fluorescence spectroscopy is an important tool for the characterization of protein folding. ${ }^{2}$ As a possible route, a protein is labeled with appropriate fluorescent donor and acceptor probes and folding-induced changes in Förster Resonance Energy Transfer (FRET) are monitored. ${ }^{3}$ However, the incorporation of two probes into a single protein for FRET studies can be difficult.

Fluorescence anisotropy is an alternative route for the characterization of protein folding. ${ }^{4}$ Measurements are based on the principle of the excitation of fluorophores by polarized light resulting in polarized emission. The polarized emission is influenced by a number of processes, including motions that occur within the lifetime of the excited fluorophore. Both intrinsic ${ }^{5}$ and extrinsic ${ }^{6}$ fluorophores can be used for fluorescence anisotropy measurements. Due to the comparable timescale of rotational diffusion of biopolymers and the fluorescence lifetime of many fluorophores, fluorescence anisotropy has been reported for numerous biological applications. Information on the shape and size of proteins can be obtained and then have been used to measure protein-protein interactions, ${ }^{7}$ fluidity of membranes, ${ }^{8}$ binding and conformational dynamics. ${ }^{9}$

In this paper, we aim at probing methanol induced unfolding of a protein by fluorescence anisotropy measurements using an extrinsic fluorophore. A simple and reliable synthesis for labeling myoglobin protein with visible Rhodamine $B$ chromophore is reported. Methanolinduced unfolding is revealed by the transition from constrained to free rotation of a covalently attached rhodamine B fluorophore.

\section{Materials and Methods}

\section{Labeling Protocol}

Myoglobin from equine skeletal muscle (Sigma-Aldrich) was labeled with Rhodamine B isothiocyanate (Sigma-Aldrich) according to a protocol slightly modified from Hungerford et al. ${ }^{10}$ as follow: reagents were dissolved so that their concentration ratio is 1 . Typically, $34 \mathrm{mg}$ of myoglobin $(\mathrm{Mb})$ and $1.1 \mathrm{mg}$ of rhodamine $\mathrm{B}$ isothiocyanate (RhB) were dissolved in 10 $\mathrm{mL}$ of $0.1 \mathrm{M}$ sodium bicarbonate buffer $(\mathrm{pH}$ 9) while stirring continuously for 2 hours at room temperature. The reaction associated to the labeling is given by: ${ }^{11}$

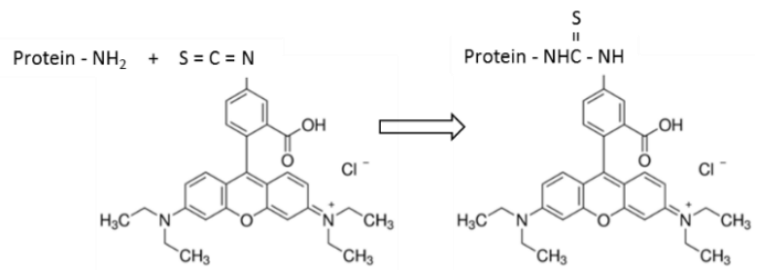

In its native form, $\mathrm{Mb}$ is a globular protein having several available amine reactive groups. ${ }^{12}$ The sequence chain of $\mathrm{Mb}$ and its $3 \mathrm{D}$ view are shown in Figure 1. Keeping the dye to protein ratio (D/P) around 1 is important to avoid any over-labeling of the protein; at most, only one dye is attached to the protein. Indeed, if the $D / P$ ratio is 
greater than 1, it can lead to strong interactions between probe dye molecules grafted onto the same protein. ${ }^{10}$ a)

MGLSDGEWQQVLNVWGKVEA DIAGHGQEVLIRLFTGHPET LEKEDKEKHLKTEAEMKASE DLKKHGTVVLTALGGILKKK GHHEAELKPLAQSHATKHKI PIKYLEFISDAIIHVLHSKH PGDFGADAQGAMTKALELFR NDIAAKYKELGFQG

b)

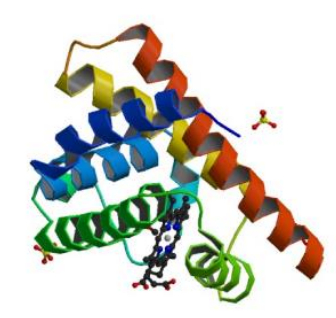

Figure 1 (a) Sequence Chain of Myoglobin. Amine groups are noted in red and $\alpha$-helix regions are highlighted in yellow (b) 3D view of Myoglobin, reprinted from Protein Data Bank (ref: 5CMV).

In order to remove any uncoupled $\mathrm{RhB}$, the solution was then dialyzed using washed tubular cellulose membranes with a nominal molecular weight cut-off at 6000$8000 \mathrm{Da}$ (ZelluTrans/Roth) against $2 \mathrm{~L}$ of 10 $\mathrm{mM}$ Phosphate Buffered Saline (PBS) at $\mathrm{pH}$ 7 for one day. Several dialysis were performed until the absorption of RhB at $555 \mathrm{~nm}$ of the final supernatant was below the detection limit. Mixture of labeled protein and unlabeled protein was then recovered as is in PBS buffer as stock solution. Stock solution concentration is evaluated by absorption to $c_{\text {stock }} \sim 200 \mu \mathrm{M}$. Fluorescence measurements are performed after a 1:10 dilution.

The final $D / P$ ratio was determined using the molar extinction coefficients of $\mathrm{Mb}$ at $408 \mathrm{~nm}\left(188000 \mathrm{M}^{-1} \mathrm{~cm}^{-1}\right)^{13}$ versus RhB one at $555 \mathrm{~nm}\left(106000 \mathrm{M}^{-1} \mathrm{~cm}^{-1}\right) .{ }^{14}$

\section{Fluorescence measurements}

An Oxxius Slim 532-300 laser (Oxxius Inc., Santa Clara, CA, U.S.A.) was used for excitation. Fluorescence intensities were determined by the steady-state fluorescence spectra maximum recorded by an Ultracompact spectrophotometer Econic (B\&WTek Inc., Newark, DE, U.S.A.) with a resolution of $1.5 \mathrm{~nm}$ via an optical fiber. ${ }^{15}$, 16

A polarizing beamsplitter cube and a halfwave plate were used to tune the linear polarity of the light on the excitation line. A linear broadband polarizer in the range 500 - $720 \mathrm{~nm}$ was used for the collection. The alignment of the setup has been performed using the pure diffusion of the polarized light by a solution containing latex nanoparticles in suspension. For each fluorescence anisotropy measurements, the

Figure 2 Schematic view of the experimental setup to measure fluorescence anisotropy $r$. The excitation and detection polarization are here vertical. The $\lambda / 2$ plate and the linear polarizer are mounted on rotation plates.

correction factor $G$ (defined below) was reevaluated. Vertically or horizontally excitations were tuned by rotating the halfwave plate by $45^{\circ}$ according to the wanted configuration and vertically or horizontally emissions were collected by rotating the linear polarizer by $90^{\circ}$ (see Figure 2).

Fluorescence lifetimes of samples were measured by a HORIBA Scientific's hybrid spectrofluorometer Fluoromax, using a pulsed nanoled excitation at $372 \mathrm{~nm}$ and collecting the emitted light at $580 \mathrm{~nm}$ with a band width of $5 \mathrm{~nm} .{ }^{17,18}$

\section{Anisotropy Fluorescence - Principle}

When a fluorophore interacts with

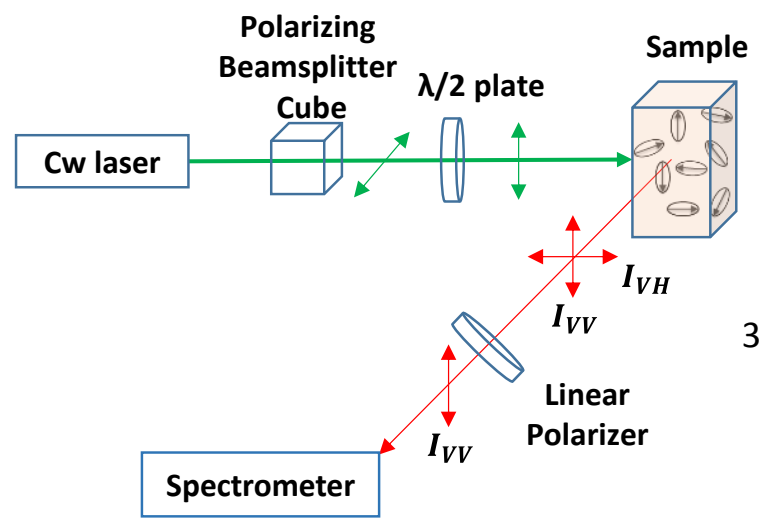


an electromagnetic wave, it can absorb a photon through the coupling of the electromagnetic field to its transition dipole moment. If the orientation of the electric filed vector of the excited light is parallel to the transition dipole moment of the fluorophore, the fluorophore can be excited efficiently. Hence, by exciting an ensemble of randomly oriented molecules with a linearly polarized light, only molecules that are aligned with the direction of the polarized excitation light are excited, so called photoselection. ${ }^{19}$

If the fluorophore moves during the life span of its excited state (Rotational Brownian motion), the emitted light polarization will be modified. To quantify this loss of polarization, we define the fluorescence anisotropy $r$ as

$$
r=\frac{I_{V V}-G I_{V H}}{I_{V V}+2 G I_{V H}}
$$

where $I_{V V}$ corresponds to the fluorescence intensity of vertically polarized excitation and vertically polarized emission, $I_{V H}$ the vertically polarized excitation and horizontally polarized emission and $G$ is a correction factor defined by

$$
G=\frac{I_{H V}}{I_{H H}}
$$

Assuming that rotational diffusion is the significant process that results a change of polarization, Perrin equation gives an expression of the fluorescence anisotropy

$$
r=\frac{r_{0}}{1+\tau / \theta}
$$

where $r_{0}$ is the limiting anisotropy that would be measured in the absence of rotational diffusion - it refers to the existence of an angle between the absorption and the emission transition dipole moments $-\tau$ is the lifetime of the fluorophore and $\theta$ the correlation time for the rotational process for a spherical objet that can by expressed from the StokesEinstein equation: ${ }^{20}$

$$
\theta=\frac{\eta V}{k T}
$$

where $\eta$ is the viscosity of the solution, $k$ the Boltzmann constant, $T$ the temperature and $V$ the volume of the rotating object.

\section{Results and discussion}

\section{Characterization of the sample}

Absorption spectra of $\mathrm{Mb}, \mathrm{RhB}$ and of the solution of the complex (RhB-labeled $\mathrm{Mb}$ ) right after the final dialysis in $10 \mathrm{mM}$ Phosphate Buffer Solution (PBS) are shown in Figure 3. The characteristic Soret band at $408 \mathrm{~nm}$ denotes the presence of the heme group on the Mb. The existence of the RhB absorption pick at $555 \mathrm{~nm}$ for the complex solution right after the final dialysis clearly indicates that the labeling occurs efficiently. We can estimate by ratiometry of the respective absorbance at 555 and $408 \mathrm{~nm}$

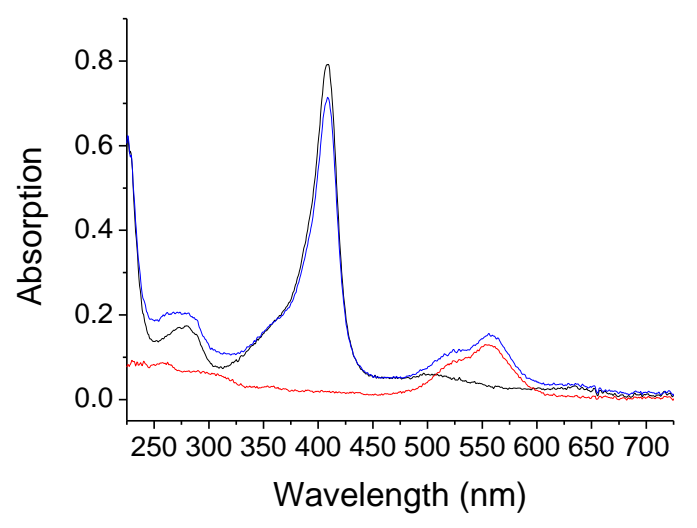

Figure 3: Absorption spectra of (black) Mb, (red) RhB and (blue) RhB-labeled Mb in 10 mM PBS buffer. 
that the $\mathrm{D} / \mathrm{P}$ ratio is approximately $1 / 3$.

Mass Spectrometry (MS) measurements of RhB-labeled $\mathrm{Mb}$ in water (PBS) are shown in Figure S1a. Characteristic peaks of holo-Mb in its native form with a low Charge State Density are clearly predominant $\left(9^{+}, 8^{+}\right.$and $\left.7^{+}\right)$, along with one-dye labeled proteins also visible in their native form with the same Charge State Density with a typical ratio consistent with the $D / P$ ratio estimated by absorbance ratiometry.

Circular Dichroism (CD) measurements of $\mathrm{RhB}$-labeled $\mathrm{Mb}$ in water (PBS) are displayed in Figure S2. Both mass spectra and $C D$ spectra confirm that the presence of a covalently attached dye onto the protein doesn't affect the structure of the protein, regarding either its Charge State Density (cf. mass spectrometry) or its secondary structure (cf. CD spectra).

Fluorescence lifetimes of the different samples are reported in Table 1 . Measurements show that attached dye fluorescence lifetimes are similar to those of dye alone in the same solution. Thus the protein backbone does not seem to affect the lifetime of the rhodamine dye. This might indicate a dye labeling at the surface of the protein which does not significantly affect the excitation lifetime. Furthermore, measured fluorescence lifetime decreases when increasing the water proportion in the solution revealing that the $\mathrm{RhB}$ fluorescence is quenched by water.

\begin{tabular}{|c|c|c|}
\hline \multirow{2}{*}{ Vol. \% of MeOH } & \multicolumn{2}{|c|}{ Fluorescence Lifetime (ns) } \\
\cline { 2 - 3 } & $\begin{array}{c}\text { Free Rhodamine B } \\
\text { isothiocyanate }\end{array}$ & $\begin{array}{c}\text { Rhodamine B } \\
\text { isothiocyanate labeled } \\
\text { on Myoglobin }\end{array}$ \\
\hline 0 & 1.75 & 1.73 \\
\hline 10 & 1.87 & 1.88 \\
\hline 20 & 1.95 & 1.98 \\
\hline 30 & 2.02 & 2.04 \\
\hline
\end{tabular}

Table 1: Fluorescence lifetime of free and RhB-labeled $M b$ in water/MeOH mixture in $10 \mathrm{mM} P B S$ buffer.
RhB alone in a PBS displays a fluorescence anisotropy of $r=0.046 \pm 0.005$ whereas for the RhB-labeled protein $r=0.199 \pm$ 0.005 . If we assume that $\mathrm{Mb}$ displays a globular shape in its native form in PBS, we can estimate that the system radius of gyration is equal to $r_{g}=1.6 \pm$ $0.1 \mathrm{~nm}$ considering a limiting anisotropy $r_{0}=0.3$, and a viscosity $\eta=$ $8.95 \times 10^{-4}$ Pa.s. This value is consistent with the literature. ${ }^{12,} 21$

\section{Parameters' influence on fluorescence anisotropy.}

According to expressions (3) and (4), fluorescence anisotropy is affected by the following main physical parameters:

(i) Temperature is a key parameter regarding Brownian motion. For high temperature, objects motion is greater resulting in a loss of anisotropy.

(ii) The size of the moving objects also greatly influence the anisotropy. The bigger an object is, the slower its rotation will be, resulting in a gain of anisotropy.

(iii) High viscosity tends to slow down the rotation motion inducing an anisotropy increase.

(iv) It is also clear that the fluorescence lifetime plays a role in the depolarization process. For short lifetime, the molecule reemits light rapidly so that it doesn't rotate enough to induce a great depolarization.

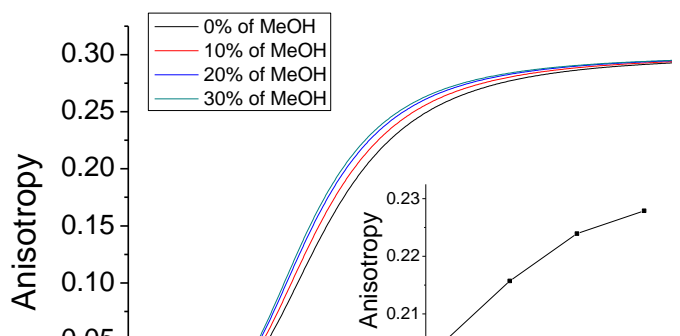

Figure 4. ¿25lculated fluprescence anisotropy regarding the radius ofgordtion of a system. Inset: Anisots apoffer a given radius of gytation $\left(r_{g}=1.6 \mathrm{~nm}\right)$ regarding the methanol $0.0\left(r_{g}=1.6 \mathrm{~nm}\right)$ regarding the methanol 4.0 Raproportion
values of $\tau$ and $\eta$ have been reevaluated $(n \mathrm{~nm})_{\text {sollow: }}$ For $0 \%$ of $\mathrm{MeOH}, \tau=1.73 \mathrm{~ns}, \eta=8.95 \times 10^{-4} \mathrm{~Pa} . \mathrm{s}$ For $10 \%$ of $\mathrm{MeOH}, \tau=1.88 \mathrm{~ns}, \eta=11.55 \times 10^{-4} \mathrm{~Pa} . \mathrm{s}$ For $20 \%$ of $\mathrm{MeOH}, \tau=1.97 \mathrm{~ns}, \eta=13.92 \times 10^{-4} \mathrm{~Pa} . \mathrm{s}$ For $30 \%$ of $\mathrm{MeOH}, \tau=2.03 \mathrm{~ns}, \eta=15.40 \times 10^{-4} \mathrm{~Pa} . \mathrm{s}$ 
We can calculate the predicted evolution of $\mathrm{RhB}$ emission anisotropy regarding the size of the rotating system (ie the radius of gyration) for a given temperature in a water/ $\mathrm{MeOH}$ mixture in the range $0-30 \%$ of methanol. ${ }^{22}$ Results are given in Figure 4 taking into account viscosity and lifetime modifications due to different solvent conditions. It is shown that for a given size, fluorescence anisotropy of a system tends to increase with the methanol proportion. Indeed, the anisotropy increase induced by the change of viscosity ${ }^{22}$ counterbalances the anisotropy loss due to the augmentation of the fluorophore lifetime.

\section{Probing unfolding of myoglobin by fluorescence anisotropy measurements}

Alcohols are well-known solvents that highly weaken hydrophobic interaction leading to strong denaturation of proteins. ${ }^{23}$ 24, 25 In order to probe protein dynamic events due to methanol ( $\mathrm{MeOH})$ addition, fluorescence anisotropy of RhB-labeled Mb has been measured as a function of methanol proportion at room temperature.

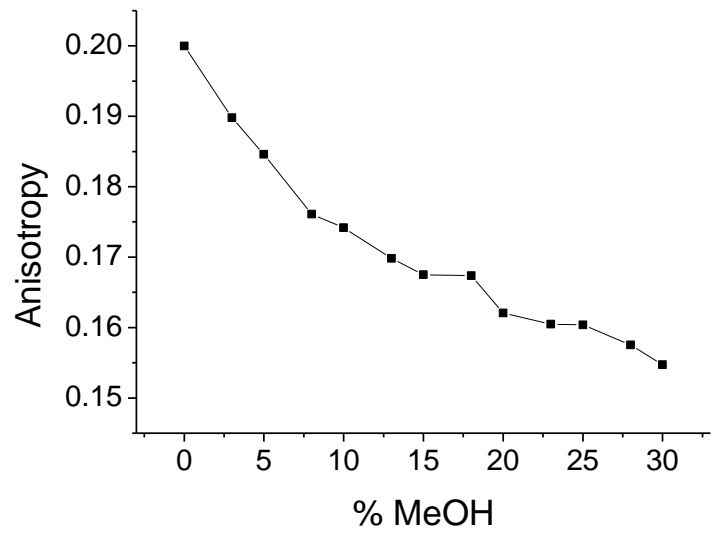

Figure 5: Fluorescence anisotropy of RhB-labeled $\mathrm{Mb}$ in water/MeOH mixture.

Results shown in Figure 5 clearly indicate a depolarization of fluorescence emission when increasing the methanol proportion.
According to the previous discussion, a loss of anisotropy may be explained by a reduction of the size of the object. However, this is inconsistent with lon Mobility Spectrometry measurements performed on Mb. Indeed, for each charge state, several conformers are observed, and a global augmentation of the cross-section occurs when the solvent is changed from water to water/methanol. ${ }^{26}$ MS measurements on $\mathrm{Mb}$ in different solvent conditions (Figure S1b) show that the average Charge State Density of Mb tends to increase with methanol which is consistent with a partial unfolding of the protein. Moreover, the signature of apo-Mb induced by the liberation of the noncovalent Heme group is observed in MS spectra and is a signature of a partial opening of the protein. Furthermore, CD analysis reveals a slight denaturation from alpha helix to unordered structure when increasing the methanol proportion (see Table S1). All these considerations are favorable to a partial unfolding of the protein leading to an augmentation of its radius of gyration.

Thus, the drop in anisotropy can only be explained as an effect of the protein unfolding. The decrease is attributable to a global unfolding which allows the fluorophore to rotate independently and freely from the protein backbone. Several models have been developed in the literature to discuss processes where independent motions of the transition dipole moment (protein chain or covalently attached chromophore) are considered. ${ }^{27-29}$ This phenomenon has already been observed on depolarization tryptophan UV emission. Indeed, the decrease was attributable to a great extent of unfolding which releases the tryptophan residue from the hydrophobic core of the protein 
allowing the indole ring to rotate independently of the protein. ${ }^{4}$ However, the anisotropy value of the system stays significantly bigger than the free fluorophore's one alone in solution because the fluorophore is still covalently attached to the protein (See Figure S3 for more details). The circular dichroism spectra reported for $\mathrm{Mb}$ have signatures that are typical for helical structure. ${ }^{26}$ One may argue that structuration of $\mathrm{Mb}$ in $\alpha$-helix upon addition of methanol avoids a strong interaction of the rhodamine $B$ dye with the protein peptidic skeleton.

\section{Conclusion}

A simple and reliable synthesis for labeling a protein with a visible chromophore is reported. Optical characterization of the system is performed through absorption spectrometry in the visible range, mass spectrometry, circular dichroism, fluorescence lifetime and fluorescence anisotropy measurements. It is shown that at most, one rhodamine B isothiocyanate molecule is grafted to myoglobin via an amine group to avoid any possible interactions within the molecules onto the same protein and no effect of the grafting can be detected regarding the main structure of the protein. Moreover, unfolding events of the protein induced by organic solvent like methanol can be probed by fluorescence anisotropy measurements. Such events are revealed by the transition from "constrained" to "free" rotation of the attached fluorophore.

The present study suggests that it should be possible, with fluorescent techniques using extrinsic fluorophores to obtain information in kinetic studies of protein folding and conformational changes.

\section{Supporting Information}

Mass spectrum of RhB-labeled $\mathrm{Mb}$ in Water (PBS) and $\mathrm{Mb}$ in different solvent conditions. Circular Dichroism spectra of $\mathrm{Mb}$ and RhB-labeled $\mathrm{Mb}$ in Water (PBS). Average values of the secondary structure for RhBlabeled $\mathrm{Mb}$ in different solvent conditions. Protocol and absorption spectra of RhBlabeled $\mathrm{Mb}$ in water (PBS) with and without the presence of methanol.

\section{Corresponding Author}

*Rodolphe Antoine : Address: Institut lumière matière, UMR5306 Université Claude Bernard Lyon1-CNRS, 5 Rue de la Doua, 69100 Villeurbanne, France. Mail: rodolphe.antoine@univ-lyon1.fr

\section{References}

1. J. R. Lakowicz, Principles of Fluorescence Spectroscopy. Third Edition. . (Springer Science+Business Media, LLC, Singapore, 2006).

2. A. S. Ladokhin, (In R. A. Meyers (ed.), Encyclopedia of Analytical Chemistry, Wiley, New York, 2000), pp. 5762-5779.

3. T. Ha, T. Enderle, D. F. Ogletree, D. S. Chemla, P. R. Selvin and S. Weiss, Proceedings of the National Academy of Sciences 93 (13), 6264-6268 (1996).

4. D. Canet, K. Doering, C. M. Dobson and Y. Dupont, Biophysical Journal 80 (4), 1996-2003 (2001).

5. A. Ghisaidoobe and S. Chung, International Journal of Molecular Sciences 15 (12), 22518 (2014).

6. A. Hawe, M. Sutter and W. Jiskoot, Pharmaceutical Research 25 (7), 14871499 (2008).

7. V. LeTilly and C. A. Royer, Biochemistry 32 (30), 7753-7758 (1993). 
8. A. Marczak, Bioelectrochemistry 74 (2), 236-239 (2009).

9. S. Weiss, Nat Struct Mol Biol 7 (9), 724729 (2000).

10. G. Hungerford, J. Benesch, J. F. Mano and R. L. Reis, Photochemical \& Photobiological Sciences 6 (2), 152-158 (2007).

11. M. Brinkley, Bioconjugate Chemistry 3 (1), 2-13 (1992).

12. J. C. Kendrew, G. Bodo, H. M. Dintzis, R. G. Parrish, H. Wyckoff and D. C. Phillips, Nature 181 (4610), 662-666 (1958).

13. A. Castro-Forero, D. Jiménez, J. LópezGarriga and M. Torres-Lugo, Journal of Applied Polymer Science 107 (2), 881890 (2008).

14. L. F. Mottram, S. Forbes, B. D. Ackley and B. R. Peterson, Beilstein Journal of Organic Chemistry 8, 2156-2165 (2012).

15. M. Girod, X. Dagany, R. Antoine and P. Dugourd, International Journal of Mass Spectrometry 308 41-48 (2011).

16. M. Girod, X. Dagany, V. Boutou, M. Broyer, R. Antoine, P. Dugourd, A. Mordehai, C. Love, M. Werlich, J. Fjeldsted and G. Stafford, Physical Chemistry Chemical Physics 14, 93899396 (2012).

17. A. Soleilhac, X. Dagany, P. Dugourd, M. Girod and R. Antoine, Analytical Chemistry 87, 8210-8217 (2015).

18. A. Soleilhac, M. Girod, P. Dugourd, B. Burdin, J. Parvole, P.-Y. dugas, F. Bayard, E. Lacôte, E. Bourgeat-Lami and R. Antoine, Langmuir (2016).

19. D. M. Jameson and J. A. Ross, Chemical Reviews 110 (5), 2685-2708 (2010).

20. D. Lavalette, C. Tétreau, M. Tourbez and Y. Blouquit, Biophysical Journal 76 (5), 2744-2751 (1999).

21. M. T. Tyn and T. W. Gusek, Biotechnology and Bioengineering 35 (4), 327-338 (1990).

22. S. Z. Mikhail and W. R. Kimel, Journal of Chemical \& Engineering Data 6 (4), 533537 (1961).
23. T. T. Herskovits, B. Gadegbeku and H. Jaillet, Journal of Biological Chemistry 245 (10), 2588-2598 (1970).

24. Q. Shao, The Journal of Physical Chemistry B 118 (23), 6175-6185 (2014).

25. A. Fernández and O. Sinanoglu, Biophys Chem 21 (3-4), 163-166 (1985).

26. J. Seo, W. Hoffmann, S. Warnke, M. T. Bowers, K. Pagel and G. von Helden, Angewandte Chemie International Edition 55 (45), 14173-14176 (2016).

27. Y. Y. Gottlieb and P. Wahl, Journal De Chimie Physique Et De Physico-Chimie Biologique 60 (7-8), 849-856 (1963).

28. K. Kinosita, S. Kawato and A. Ikegami, Biophysical Journal 20 (3), 289-305 (1977).

29. G. F. Schröder, U. Alexiev and H. Grubmüller, Biophysical Journal 89 (6), 3757-3770. 